\title{
Application of Electrical Automation in Solar Photovoltaic Power Generation
}

\author{
Ren Chao \\ Jiangxi Vocational College of Industry information Engineering, Pingxiang, Jiangxi, 337000, China \\ renchao12@126.com
}

Keywords: solar energy; photovoltaic power generation; electrical automation.

\begin{abstract}
With the continuous progress of society, people pay more attention to environmental protection and energy issues, so the use of renewable energy and non-polluting energy has been widely concerned. Solar energy is currently one of the most promising energy sources, not only unlimited reserves, but also more convenient and fast to use. At present, the most common is to use photovoltaic power generation equipment to convert solar energy into electricity. Because of the complexity of the solar photovoltaic power generation system, electrical automation is often used to optimize the system control to maintain the stability of photovoltaic power generation. Based on this, taking solar photovoltaic power generation as an example, this paper focuses on the analysis of the application of electrical automation in solar photovoltaic power generation, and discusses the development trend of the application of electrical automation in solar photovoltaic power generation.
\end{abstract}

\section{Overview of solar photovoltaic technology}

Solar photovoltaic power generation is to use the principle of photovoltaic power generation to convert solar energy into electricity, power generation system is mainly a variety of electronic components, not including mechanical components. From the current technology, solar photovoltaic power generation equipment is not only simple, but also the use of reliability, a wide range of applications, from spacecraft to children's toys have a strong applicability. And the traditional fuel energy is decreasing, the global energy supply has been unable to meet social needs. Therefore, the development of solar photovoltaic power generation is very rapid, the scale of related industries is expanding, and the technology is gradually improving and maturing.

In the 21st century, the world is advocating green energy, so solar photovoltaic power generation technology is strongly supported by governments, which has become a new trend of energy utilization. In solar photovoltaic power generation, Japan, the United States and Germany and other countries are more advanced in technology, they have a wealth of development experience, while the coverage of solar photovoltaic power generation is also large. In addition, the economy has developed to a certain extent, and the level of science and technology is relatively developed, which can lay a good foundation for the rapid development of solar photovoltaic power generation. With the maturity of solar photovoltaic power generation technology abroad, China has also begun to gradually popularize solar photovoltaic power generation technology, based on sustainable development of solar energy utilization, in Jiangxi, Jiangsu, Hebei and Sichuan and other places have formed industrialization development, so that solar photovoltaic power generation has penetrated into many fields. . Specifically, the application fields of solar photovoltaic power generation are as follows:

(1) Solar power for individual users. Individual users of solar power supply is generally small, often less than $100 \mathrm{~W}$, is very common in remote areas, such as pastoral areas, islands and plateaus, the conversion of energy is also mainly used for lighting, radio and television.

(2) Traffic area. Traffic signal lights, high-altitude obstacle lights, traffic signs and so on often use solar photovoltaic power generation, which consumes less energy, so solar photovoltaic power generation can fully meet the requirements.

(3) Meteorological monitoring. Meteorological monitoring equipment needs long-term 
uninterrupted work, and most of them are in an inconvenient environment, so solar photovoltaic power generation is usually used to maintain the operation of equipment, such as hydrological monitoring equipment and meteorological monitoring equipment.

(4) Photovoltaic power station. Photovoltaic power station is a large-scale construction of photovoltaic power generation equipment, its power is often between $10 \mathrm{KW}$ - 50MW, can be incorporated into the national grid or exist alone. At present, photovoltaic power station is the most important form of solar photovoltaic power generation and plays the most important role.

With the continuous improvement and improvement of solar photovoltaic power generation technology, the current application of solar photovoltaic power generation is more extensive, ranging from large-scale national projects to daily household appliances, there are the shadow of solar photovoltaic power generation. Moreover, compared with the traditional solar photovoltaic system, the current solar photovoltaic power generation has been significantly improved, the power generation is greater, the operation of the system is more stable, can greatly facilitate people's lives.

\section{Application of electrical automation in solar photovoltaic power generation}

Electrical automation technology has very superior performance, it can realize the independent operation of equipment, through remote monitoring can also be human intervention, reducing the labor intensity of staff, but also conducive to maintaining the stability of the system. In the current power industry, the application of electrical automation technology is very extensive, which can improve the operation efficiency of power system and increase the economic benefits of power enterprises. The same is true for solar photovoltaic power generation. The following is the specific application analysis.

\subsection{Photovoltaic building and photovoltaic pump systems}

There are many solar panels in photovoltaic pumping system and photovoltaic buildings, so it is necessary to monitor the power generation of the solar panels in use, and then it can play the role of electrical automation. Electrical automation system can use communication mode and monitoring software to realize the operation of multiple individuals monitoring, and can be based on feedback monitoring data for individual control, which can improve the stability and security of operation.

Taking photovoltaic building as an example, it has a higher requirement for photovoltaic modules, not only to take into account the power generation, but also to meet the basic functional requirements of the building. In addition, it is individual use, so we must strengthen control and take safety and stability as the core objectives. Therefore, in the whole photovoltaic building, electrical automation is an important part of its system, through the monitoring system and automatic control system, eliminate the external factors of photovoltaic building power generation, as far as possible to maintain the stability of photovoltaic power generation.

\subsection{DC inverter control for solar photovoltaic power generation}

Photovoltaic power generation system is also a large power generation, it can be converted to solar energy in a short time, if a large number of solar panels together, its power generation capacity is no less than the traditional power generation mode. So the current photovoltaic power generation system is more used in the national grid, can play a supplementary role in electricity, reduce the pressure of the national grid. However, solar photovoltaic power generation generates direct current, if it is incorporated into the national grid, it needs to be converted, which is used in DC inverter control. In solar photovoltaic power generation system, DC inverter control mainly includes transformer, power conversion device, photovoltaic cell module and battery pack. If the traditional current conversion method is used, not only its adaptability is poor, but also it is easy to occur conversion problems, resulting in the stability of photovoltaic power generation when incorporated into the national grid. The sex is poor. At this point, the introduction of electrical automation control technology, through this technology can be specific to each stage of the specific parameters of energy conversion, and then make targeted adjustments to ensure that the photovoltaic power generation system generated 
electricity into the national grid security and reliability.

\subsection{Solar photovoltaic grid connected system}

Solar photovoltaic power generation system in normal operation will be based on the characteristics of the power generation mode to a reasonable collocation, because the power consumption is different, so in different periods to judge the power generation mode reasonably, so as to reduce the impact of photovoltaic power generation system on the national grid. This is because solar energy is not stable, weather and other factors will affect the power of photovoltaic power generation, this time the stability of the power generation system can not be effectively guaranteed. Therefore, it is necessary to introduce electrical automation control technology to make logical judgments by collecting the electricity on both sides of the grid in different periods, and at the same time to issue the power grid consolidation order in advance according to the grid connection demand, so as to maximize the reduction of voltage deviation and maintain the power supply stability of the National grid.

\subsection{Reactive power compensation control of solar photovoltaic power generation}

Solar photovoltaic power generation system uses a large number of electronic components, it is easy to generate harmonic and reactive power loss in the whole system, this phenomenon will lead to the instability of the whole solar photovoltaic power generation system, in many cases the quality of voltage can not meet the required standards, which is also solar photovoltaic power generation and traditional power generation. The disadvantages are compared. But this problem can be effectively solved by the electrical automation control system, through the electrical automation control can very accurately detect the actual demand for reactive power loss, and then through a wide range of regulation to control the voltage quality, in order to ensure the stability of solar photovoltaic power generation system. And this process does not require human intervention, through the computer system and electrical automation control system can be achieved independently, which is conducive to improving the efficiency of solar photovoltaic power generation system, but also conducive to ensuring the stability of the entire system.

\subsection{Life cycle control of solar photovoltaic system}

In the traditional solar photovoltaic power generation system, the maintenance of electrical equipment is after the equipment problems, this phenomenon will affect the reliability and stability of the power supply system operation, at the same time, due to the lack of necessary maintenance work, will shorten the service life of electrical equipment, increase the operation cost of the grid system. The introduction of electrical automation control technology can solve this problem very well, because electrical automation control technology can monitor all the equipment in the process of power grid operation, and feedback its operation state, so that the computer can effectively judge whether there is a fault of electrical components, and then reasonably formulate inspection. Maintenance and maintenance plan can effectively ensure the operation stability of solar photovoltaic power generation system, but also conducive to extending the service life of equipment, reduce the operation cost of grid enterprises.

On the whole, the electrical automation control technology plays a very important role in the solar photovoltaic power generation system. It effectively improves the intelligent level of the whole system, but also conducive to ensuring the stability of the system operation. After entering the 21st century, the state vigorously builds the power grid system, but also strives to enhance the intelligence of the power grid, in order to ensure the efficiency and reliability of power supply. The same is true for solar photovoltaic power generation systems, so electrical automation technology is playing an increasingly important role. Essentially, electrical automation control technology is a technical means of collecting signals, feedback signals and automating logic operation. Introducing it into solar photovoltaic power generation system can reduce the influence of human factors on the stability of the system, and give feedback action quickly for complex parameters, so it can be large. The amplitude reduces the interference of external factors to the reliability of power grid, and effectively 
optimizes the power supply network.

\section{Development trend of application of electrical automation in solar photovoltaic power generation}

China has a large land area and abundant solar energy resources, which lays a solid foundation for solar photovoltaic power generation. And from the international trend, the use of solar energy will become the mainstream, which is in line with the sustainable development strategy, but also conducive to environmental protection. Especially in recent years, China's economic development has been accelerated gradually, and there is a greater demand for electricity, which requires constant supplementary power generation methods to ease the pressure of power supply. Therefore, solar photovoltaic power generation must accelerate the pace of development, while optimizing their own systems, improve stability and reliability. Electrical automation control technology plays a very important role in the optimization of solar photovoltaic power generation system. It can reduce the input of manpower, and also can effectively monitor and feedback the operation process of the system. It is also of positive significance to ensure the safety of the computer system. Therefore, the deepening application of electrical automation technology in solar photovoltaic power generation system will inevitably become the trend and trend of future development. At present, most of China's power generation is still from thermal power generation, which brings great pressure to the environment, and there is also a large waste of resources. Although this stage is inevitable, it will inevitably be gradually reduced in the future development. The proportion of power generation will be gradually replaced by clean energy and renewable energy. The traditional way of generating electricity.

\section{Conclusions}

At this stage, solar photovoltaic power generation system has a very wide range of applications in China, and in order to achieve the optimization of photovoltaic power generation system and enhance its stability, the application of automation control technology is becoming more and more mature, while the application of a wider range of areas, both of which form a virtuous cycle. Therefore, this paper starts with the overview of solar photovoltaic power generation technology, focusing on the analysis of the application of electrical automation technology in solar photovoltaic power generation, respectively, from the photovoltaic building and photovoltaic water pump system, solar photovoltaic power DC inverter control, solar photovoltaic grid-connected system, solar photovoltaic power generation reactive power compensation control Five aspects of equipment life cycle control of solar photovoltaic power generation system are studied, and the specific application mode and functional advantages of electrical automation control are discussed in detail. Finally, combined with the actual situation of the current society, the development trend of the application of electrical automation control in solar photovoltaic power generation is analyzed, hoping to provide certain direction for the optimization of solar photovoltaic power generation system and the deepening of the application of electrical automation in solar photovoltaic power generation.

\section{Acknowledgements}

Science and technology research project of Jiangxi Provincial Department of Education: Research on control technology of distributed photovoltaic power station based on Plc

Item number GJJ171283

\section{References}

[1] Wang Zhenjie. The application of electrical automation in solar photovoltaic power generation [J]. China's strategic emerging industries, 2018 (04): 37. 
[2] Huang Hongwei. Application of electrical automation in solar photovoltaic power generation [J]. Shandong Industrial Technology, 2018 (17): 183.

[3] Liu Xiaodong. Application analysis of electrical automation in electrical engineering [J]. Intelligent City, 2016,2 (02): 202-204.

[4] Ma Jianhua. Application and Innovation of Digital Technology in Industrial Electrical Automation [J].Manufacturing Automation, 2012,34(06): 142-144.

[5] Hu po, Xin Songxu, Bai Jianhua, Zhang Yunzhou. Research on the development and absorption of solar power in China [J].China Electric Power, 2013, 46 (01): 1-6.

[6] Hu Keqiang. Application of Electrical Automation in Electrical Engineering [J].China Hi-tech Enterprise, 2013 (05): 40-42.

[7] Li Mengda. Power quality time-frequency analysis and control strategy research of micro-grid based on solar power generation [D]. Northeast Petroleum University, 2016. 